\title{
On the Face of It: Social Heuristics Are Mediated by Age and Sex, But Not by Faciometrics
}

\author{
Julia M. Robertson ${ }^{*}$, Barbara E. Kingsley
}

School of Human and Social Sciences, Buckinghamshire New University, Queen Alexandra Road, High Wycombe, Buckinghamshire, HP11 2JZ, UK; E-Mails: julia.robertson@bucks.ac.uk; Barbara.Kingsley@Bucks.ac.uk

* Correspondence: Julia M. Robertson; E-Mail: julia.robertson@bucks.ac.uk

Academic Editor: Donatella R. Petretto

OBM Geriatrics

2020 , volume 4 , issue 2

doi:10.21926/obm.geriatr.2002124
Received: February 16, 2020

Accepted: June 19, 2020

Published: June 23, 2020

\begin{abstract}
The ability to situate individuals within social categories provides an important social function, allowing people to navigate problems of survival and reproduction within highly complex social structures. This categorization of people with apparently shared characteristics is facilitated by various cues, one of the most important being facial information. There has been a wealth of literature that reports on perceptions of characteristics informed by faciometrics (or the measurement of facial features and associated ratios), but little considers the impact of aging on these social heuristics. This study therefore considers the impact of age and sex on the perception of four characteristics, these being physical power, social power, intelligence, and warmth from a sample of 120 participants recruited online. Participants were asked to rate images for one of the four characteristics in 20 men and 20 women representing each of three age groups - young adults, adults in middle age and older adults. Analyses indicated that physical power is perceived to diminish in men (but not women), social power is perceived to increase in women (but not men), and intelligence is perceived to increase in both sexes, though whilst men are perceived to be significantly more intelligent than women in middle age, in old age women are perceived to be significantly more intelligent than men. Age was not shown to impact perceptions of warmth. Perhaps surprisingly, whilst 'macro factors' (age and sex)
\end{abstract}

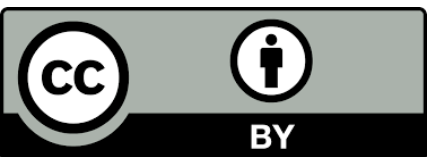

(C) 2020 by the author. This is an open access article distributed under the conditions of the Creative Commons by Attribution License, which permits unrestricted use, distribution, and reproduction in any medium or format, provided the original work is correctly cited. 
supported this social decision making, faciometrics, almost comprehensively, did not. It is suggested, then, that social heuristics rely on simple, quick and efficient stereotyped decision making through broad brush categorizations e.g. young, middle aged or old, male or female.

\section{Keywords}

Aging; faciometrics; facial metrics; fWHR; social heuristics

\section{Introduction}

Humans are highly social animals, living in groups in order to solve problems of survival and reproduction effectively [1]. The distinctive social skills needed to navigate the demands of such group living, however, are multifaceted and any information available to support success in this respect will be valuable. As such, the effective navigation of our social world requires our ability to generalize from known 'cases' to similar, unknown ones [2]. Stereotypes, or the categorization of people with apparently shared characteristics, facilitate such mental shortcuts, and, assuming some accuracy, perceptions of another's characteristics should allow us to respond appropriately within the social context. Conversely, overgeneralizations resulting in errors would be deemed to be less maladaptive than failure to respond to the apparent cues given [2].

In order to draw on stereotypical information it is, of course, necessary to situate the individual within a social category [3]. One of the first sources of such information comes, on first meeting, from an individual's appearance and particularly their face. Perceived age, race, and gender provide immediate information alongside other, perhaps less obvious information. Humans frequently make judgments about personality, for example, from facial information alone, and such judgements are almost instantaneous and resistant to change in the absence of further information $[4,5]$.

So how accurate are perceptions based on facial appearance alone? There is some (though not equivocal) evidence to support accuracy with regard to extraversion, agreeableness, conscientiousness, emotional stability and openness [6-9], though women may be stronger in this respect than men [10]. Other research, on the other hand, has found no relationship between selfreported agreeableness and conscientiousness and ratings for these traits by others [11], whilst 3D facial models evidenced specific facial patterns in these two personality factors [12]. Further research has indicated correlations between self-reported and other-rated warmth, approachability and aggression in men, and self-reported and other-rated physical power and assertiveness in women [13]. As Little and Perrett [7] point out, however, the veracity of a stereotype is of no consequence when considering consistency in stereotypical attributions.

Independent of their veracity, then, facial characteristics are used to convey to the perceiver information about that individual, and it is from this information that we start to make stereotypical inferences about expected behaviours, beliefs and attitudes based upon the social category into which they have been situated (e.g. old/ young, introvert/ extravert etc.). The facial cues which allow categorization into one group may, however, be overgeneralised into other groups (or individuals within those groups) in whom similar facial cues are seen. For example, 
adults respond positively to the cute features of infants (e.g. large eyes, large foreheads, small noses and small chins), as evidenced through increased looking time [14], more focussed attention [15], faster attentional biases [16] and cardiac acceleration and increased smiling when viewing images of smiling infants. This effect is seen in both men and women [17], and is consistent, too, with the infants of other species, with, for example, 'cute' (neotenous) puppies being more likely to receive a toy and to be hypothetically adopted than their less cute counterpart [18].

Such positive attention demonstrates an evolved response to the need for parental care and ensures the care and protection of altricial infants. Importantly, research also shows that adults with the neotenous features of infants stimulate patterns of neural activation comparable to their younger counterparts [19] and, independent of their attractiveness, are also rated to be more childlike (more naïve and submissive, less strong, dominant and competent) than their peers [20, 21]. Examples evidencing the real world impact of such attributional biases include the findings that neotenous faces are more likely to receive help and cue social approach (as evidenced through the returning, or otherwise, of 'lost', posted résumés) in both white and black females and white (but not black) males [22], that others rate greater motivation to take care of them [23], that the facial appearance of litigants' and plaintiffs affects judicial decisions (such that baby-faced defendants were more likely to win cases involving intentional actions and baby-faced plaintiffs received larger monetary rewards; [24]), and that females are more likely to express positive adoption attitudes towards baby faced infants [25].

So what facial cues are used to make predictions about perceived characteristics? We know that baby-faced characteristics - large eyes, large forehead etc, lead to perceptions of, for example, naivety and submissiveness. There is also a wide literature that evidences the use of specific metrics in our understanding of a comprehensive range of personality and behavioural traits. For example, there is a wealth of literature utilising the facial width to height ratio (fWHR), or the ratio between bizygomatic width (or the width between zygions or cheekbones) and upper face height (as measured from the upper lip midpoint to the nasion). Whilst meta-analysis indicates that fWHR is not sexually dimorphic [26], there is consistent evidence linking fWHR with actual aggression (see meta-analyis by Haselhuhn, Ormiston \& Wong, [27]) and gender or dominance related behavioural correlates. For example, higher fWHR has been associated with higher scores of trait dominance and reactive aggression in both a behavioural task and in a naturalistic setting (varsity and professional ice hockey [28]). Further, positive correlations have been found between self-rated aggression and other-rated propensity for aggression in men photographed displaying neutral facial expressions [29], actual and perceived physical formidability [30], estimates of aggression from emotionally neutral faces [31], and prediction of male offender aggression [32] (though perceived aggression in women through fWHR is weaker; [33]). fWHR has also been linked to the explicit endorsement of racially prejudiced beliefs [34], the likelihood of engaging in unethical behaviour [35] dehumanisation [36] and achievement drive in US presidents [37].

Similar findings have also been reported in non-human species, with greater fWHR seen in species of macaques characterised by a despotic female dominance style (e.g. Formosan rock macaques, Macaca cyclopis, and Japanese macaques, (Macaca fuscata) in comparison to more tolerant species (e.g. crested black macaques, Macaca nigra, and Tonkean macaques, Macaca tonkeana [38]). Additionally, assertiveness (but not dominance) was associated with fWHR in rhesus macaques (Macaca mulatta), but only in individuals younger than 8 years of age [39]. 
Positive associations have also been found between fWHR and both alpha status and a dimensional rating of assertive personality in brown capuchin monkeys (Sapajus apella) [40], and assertiveness and agonistic dominance both predicted fWHR in bonobos (Pan paniscus; [41]). However, virtually no association was found between fWHR and dominance (in addition to other personality components) in captive chimpanzees (Pan troglodytes, P.t. verus, P.t. schweinfurthii and P.t. troglodytes [42]).

As with primates, findings in humans, too, have not been unequivocally supported. Indeed, in a large scale, real world study conducted by Kosinski [43], 55 self-reported behavioral tendencies associated with anti-social behavior were measured and found to have little to no relationship with fWHR, suggesting that the apparent consensus in previous findings (frequently reporting marginal significance) may be explained both by degrees of freedom and by the general issues surrounding publication bias and the tendency not to submit papers for review which fail to reject the null hypothesis. Kosinski's [43] findings have been further supported by [44], who similarly used a large scale sample but extended the research to include both focal individuals (i.e. selfreport) and evaluators, all of whom reported to know the focal individuals well. Again, they found no evidence for a relationship between $\mathrm{FWHR}$ and anti-social tendencies. Rather, they suggest that an evolutionary mismatch may explain perceptions of anti-social behavior. In other words, in our ancestral environment in which violence was prevalent, a broader fWHR may then have reliably been linked to anti-social behaviors, whereas in the novel environment such behaviors may no longer be accurately predicted, though the biased perception remains [45].

Faciometric studies have also employed other measures, however, most notably measures of cheekbone prominence, the lower face to full face height ratio and the face width to lower face to height ratio. These have been used to investigate a diversity of topics including, for example, facial attractiveness per se, e.g. [46-52] and in environmental context, e.g. [53 ], health, weight, and developmental change, e.g. [54-56], mate choices, e.g. [57], sexual orientation, e.g. [58-60], facial masculinity/ femininity and testosterone levels, e.g. [61-66] and sexual dimorphism crossculturally and over the life span [67-69]. They have also been used, as with the fWHR research, to measure personality traits in other species (e.g. capuchin monkeys, Sapajus apella [70].

So humans use facial information from which they make stereotypical attributions, and faciometrics have been widely utilised to understand the particular facial features (or configurations of them) associated with these attributions. However, our understanding of stereotypical perceptions based upon such facial information has largely neglected to consider the role of aging and its impact upon these perceptions. There is, regrettably, a dearth of literature in this area. In one exception to this, in a paper specifically designed to consider the impact of aging on faciometrics, evidence is provided to suggest that these information-giving metrics are not static, but rather change over time [68]. Further, evidence shows that these metrics change differentially with, for example, cheekbone prominence and the facial width to height ratio changing relatively little as we age in comparison to the lower face to full face height ratio which shows significantly greater instability. Indeed, the only known characteristic investigated over age in relation to social perceptions is fWHR, which characteristic has been shown to depreciate over age $[3,69]$ and which has been shown to differentially impact age-related perceptions of social power, physical power and wisdom.

In order to address this important gap in the literature, the current study therefore proposes to conduct a partial replication of the Hehman et al study [3] by investigating the perceptions of four 
social constructs (perceived physical power, perceived social power, perceived intelligence and perceived warmth) in different age groups, i.e. in young adults, middle-aged adults, and an older age group. We extend this work in terms of sex (the former study being conducted on just male faces) and facial metrics employed (the former study focussing on fWHR, whilst the current study extends that to consider other empirically salient faciometrics, those being cheekbone prominence, the lower face to full face height ratio and the face width to lower face to height ratio - see Figure 1 for diagrammatic information). By so doing we aim to provide further understanding in the field of social perceptions, stereotyping and their association with aging.

\section{Participants and Methods}

\subsection{Participants}

A convenience sample of 120 participants completed the study, 94 females $(M=29.115, S D=$ 11.49) range $=50,21$ males $(M=27.05, S D=11.25)$ range $=38$, and two who did not provide sex details.

Ethical approval of the project (working title), "Faciometrics and their mediation of age-related social heuristics" was granted by Buckinghamshire New University's Research Ethics Panel on May $24^{\text {th }}, 2019$.

\subsection{Materials}

Following previous research $[68,69]$ images were drawn from the MORPH longitudinal database [71], of 13,000 individuals and 55,000 facial photographs. Other images were also selected from the FACES database [72] containing 2,052 images of young, middle-aged and older women and men and all images were collated. In total, the images represented 20 males and 20 females from each of the following age groups: twenties and thirties (representing the young adult group); forties and fifties (representing the middle-aged group); and sixties and seventies (representing the older age group). Selection criteria required that all faces were classified as White European, and in accordance with established protocols, all were forward-facing, neutral in expression, and none wore glasses. In addition, any images that precluded accurate facial measurements (e.g. due to hairstyle or clothing) were also excluded. All images were rated on a scale of 0 to 100 using a visual analogue scale, a high score indicating high levels of the relevant variable. The task was self-paced, the images being presented to participants in a random order, one at a time. Open-source software, ImageJ (Version 6), was used to take facial measurements.

\subsection{Facial Measures}

In line with previous research (e.g. [67]), the four facial metrics investigated were facial width to facial height ratio ( $f W H R$ or a/e), cheekbone prominence (ChP or $a / b$ ), lower face to full face height ratio (LF/FFH or c/d) and face width to lower facial height ratio (fWLHR or a/c). See Figure 1. 


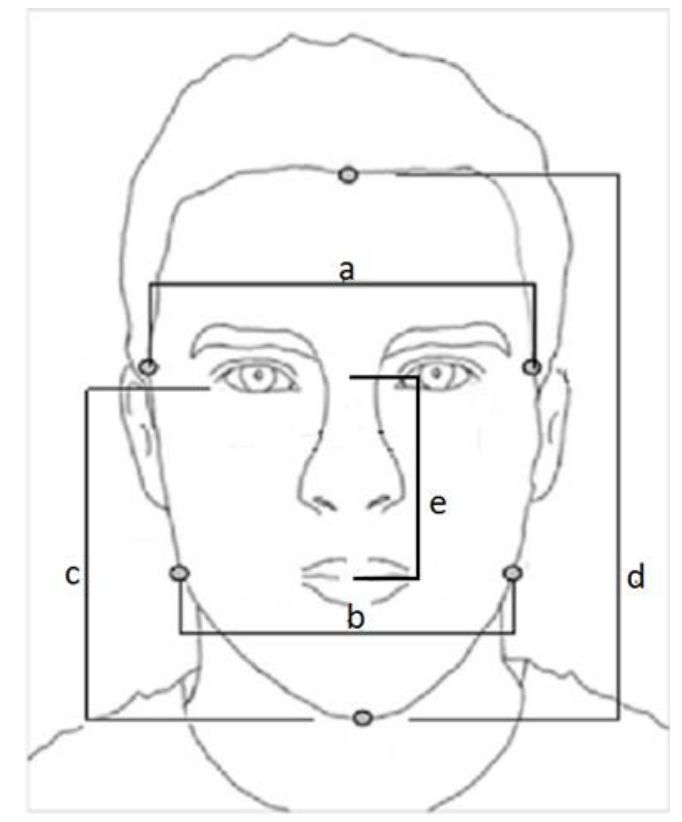

Figure 1 Points used in the calculation of facial metrics.

\subsection{Design}

As a partial replication of the Hehman et al study [3], this study employed a between-groups design in which participants rated the images for either physical power, or social power, or intelligence or warmth, with no further explanation or description, dependent upon the group into which they had been allocated. The terms used were not elaborated with further descriptors in order to allow The images rated represented multiple images including both men and women and from each of the three age groups.

The factors were, therefore, the age of each image (young adult, middle-aged or older adult) and sex (male or female). Initial 2 (sex) $\times 3$ (age group) ANOVAs were conducted for each social construct (perceived physical power, perceived social power, perceived intelligence and perceived warmth). Subsequent multiple regression analyses were conducted, the outcome variable being the mean score for each social construct, while the predictor variables were the four facial measurements.

\section{Results}

\subsection{Perceived Physical Power}

Gender and age differences were initially investigated by way of a $2 \times 3$ between groups analysis of variance (see Table 1). The first factor, Sex, had two levels (Male, Female) and the second factor, Age Group had three levels (Young, Middle, Old). The dependant variable was the score for perceived physical power. There was a statistically significant main effect for sex, $F(1$, $114)=137.37, p$ s.001, partial $\eta^{2}=.55$, with men $(M=54.96, S D=13.47)$ being perceived as more physically powerful than women $(M=38.17, S D=7.33)$. There was also a statistically significant main effect for age group, $F(2,114)=23.67, p<.001, \eta_{p}{ }^{2}=.29$, with additional post hoc analysis using Bonferroni comparisons indicating that there were significant differences between all age groups - $p$ c.001 between the older age group $(M=40.12, S D=10.68)$ and middle age group $(M=$ 
$47.49, S D=13.24)$, and the older age group and younger age group $(M=52.08, S D=14.32) ; p=.03$ between the younger age group and middle age group. Finally, there was a significant interaction effect between the two factors, $F(2,114)=32.00, p<.001, \eta_{p}^{2}=.36$ (see Figure 2).

Table 1 Descriptive statistics for age group and sex for perceived physical power.

\begin{tabular}{rrrr}
\hline \multicolumn{1}{c}{ Age Group } & \multicolumn{1}{l}{ Gender } & \multicolumn{1}{c}{$M(S D)$} & $95 \% \mathrm{Cl}$ \\
\hline Young & Male & $64.88(7.95)$ & {$[61.15,68.60]$} \\
& Female & $39.29(3.60)$ & {$[37.61,40.98]$} \\
Middle & Male & $59.59(5.60)$ & {$[56.97,62.21]$} \\
& Female & $35.39(4.54)$ & {$[33.27,37.52]$} \\
Older & Male & $40.41(10.97)$ & {$[35.28,45.55]$} \\
& Female & $39.82(11.00)$ & {$[34.67,44.97]$} \\
& Total Male & $54.96(13.47)$ & {$[51.45,58.44]$} \\
& Total Female & $38.17(7.33)$ & {$[36.27,40.06]$} \\
\hline
\end{tabular}

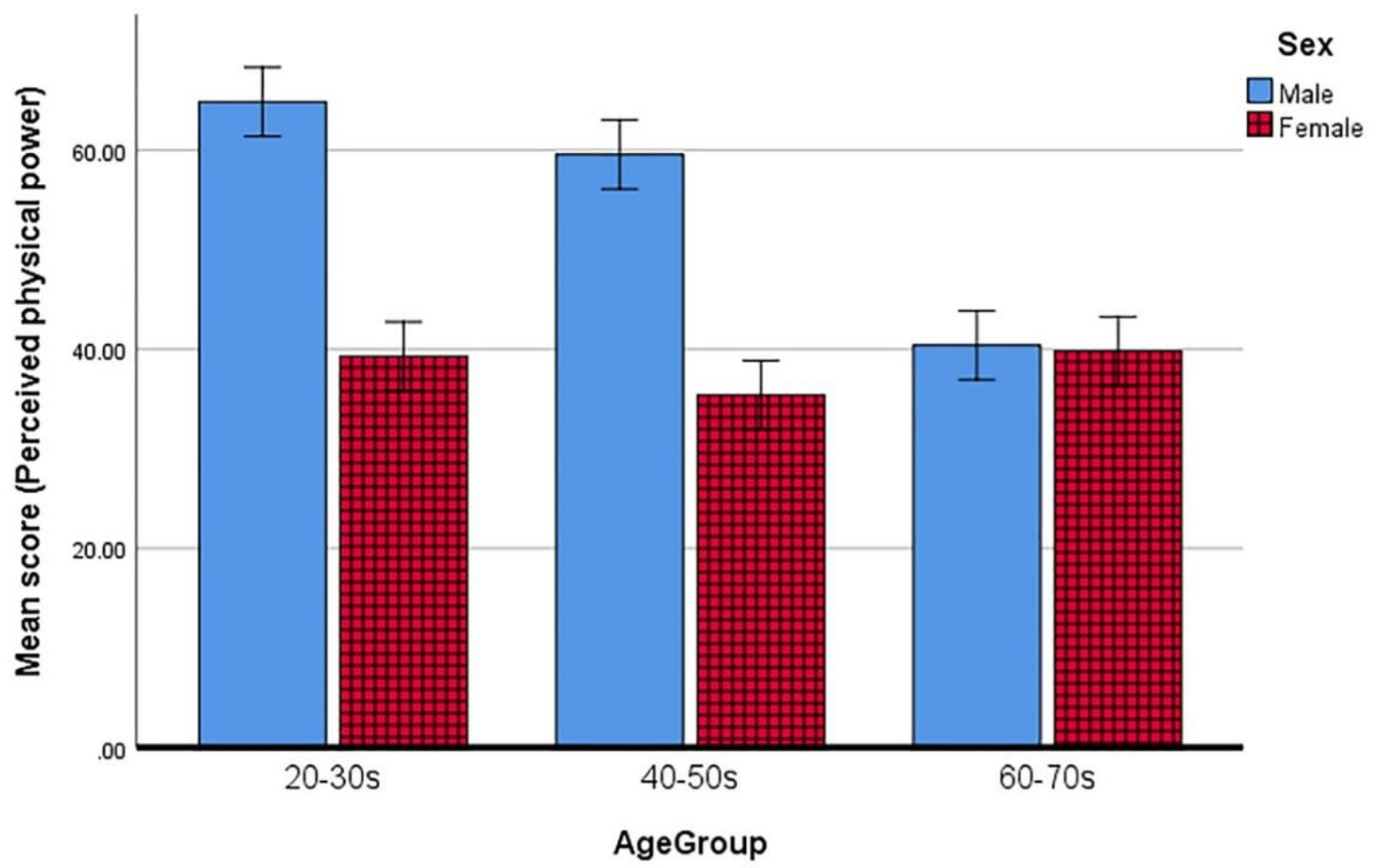

Error bars: $95 \% \mathrm{Cl}$

Figure $\mathbf{2}$ Interaction between sex and age group for mean perceived physical power scores.

Simple effects analyses showed that males were perceived to be significantly more powerful than females in both the young and the middle age groups, $t(26.48)=13.10, p<.001$ and $t(38)=$ $15.02, p<.001$ respectively, but not in the older age group $p=$ NS. In addition, when looked at separately, there was a significant difference between each of the age groups for men (young $M=$ 
64.88, $S D=7.95$; middle $M=59.59, S D=5.59$; old $M=40.42, S D=10.97), F(2,57)=46.26, p<.001$, $\eta_{\mathrm{p}}{ }^{2}=.62$, but not for women.

Simple regression analyses were also conducted to assess the ability of the four faciometrics measures ( $\mathrm{WWHR}, \mathrm{ChP}$, LfhFfh and fWLHR) to predict perceived physical power for each age group and gender. In the middle age group, three of the measures offered some predictive power in relation to males and females overall. For fWHR the total variance explained by the model was $12.6 \%, F(1,38)=5.48, p=.025$, for ChP the total variance explained by the model was $11.6 \%$, $F(1,38)=4.97, p=.032$, and for fWLHR the total variance explained by the model was $20.8 \%$, $F(1,38)=9.98, p=.003$. In the younger age group fWLHR also offered some predictive power in relation to males and females overall, the model accounting for $19.3 \%$ of the variance, $F(1,38)=$ $9.10, p=.005$. The only metric to predict physical power for individual sexes was LfhFfh in relation to males in the middle age group, the model accounting for $22.3 \%$ of the variance, $F(1,18)=5.16$, $p=.036$.

\subsection{Perceived Social Power}

For this social construct there was a statistically significant main effect for age group, $F(2,114)$ $=11.28, p<.001, \eta_{p}{ }^{2}=.17$, with additional post hoc analysis using Bonferroni comparisons indicating significant differences between the older age group $(M=36.74, S D=9.58)$ and the younger age group $(M=31.02, S D=8.22), p=.009$, and the middle age group $(M=28.89, S D=8.46), p<.001$, but not between the younger and middle age groups (see Table 2). The interaction was also statistically significant, $F(2,114)=6.04, p=.003, \eta_{p}{ }^{2}=.10$, simple effects analyses showing that while there was a non-significant trend for males to be perceived as more socially powerful than females in the young and middle age groups, women $(M=40.52, S D=10.52)$ were perceived to be significantly more socially powerful than men $(M=32.96, S D=6.90)$ in the older age group $t(38)=2.69, p=.01$.

Table 2 Descriptive statistics for age group and sex for perceived social power.

\begin{tabular}{rrrr}
\hline Age Group & Gender & \multicolumn{1}{c}{$M(S D)$} & $95 \% \mathrm{Cl}$ \\
\hline Young & Male & $32.56(8.86)$ & {$[28.81,36.30]$} \\
& Female & $29.49(7.44)$ & {$[25.75,33.24]$} \\
Middle & Male & $30.11(7.72)$ & {$[26.37,33.85]$} \\
& Female & $25.67(8.77)$ & {$[21.93,29.42]$} \\
Older & Male & $32.96(6.90)$ & {$[29.22,36.71]$} \\
& Female & $40.52(10.52)$ & {$[36.78,44.27]$} \\
& Total Male & $31.88(17.84)$ & {$[29.71,34.04]$} \\
& Total Female & $31.90(10.89)$ & {$[29.74,34.06]$} \\
\hline
\end{tabular}

Regression analyses were conducted to establish whether any of the four faciometrics measures ( $f W H R, C h P$, LfhFfh and fWLHR) were able to predict perceived social power, both in relation to sex (Male, Female) and to age group (Young, Middle, Old). However, none of outcome models were significant, indicating that faciometrics do not readily predict perceived social power (Figure 3). 


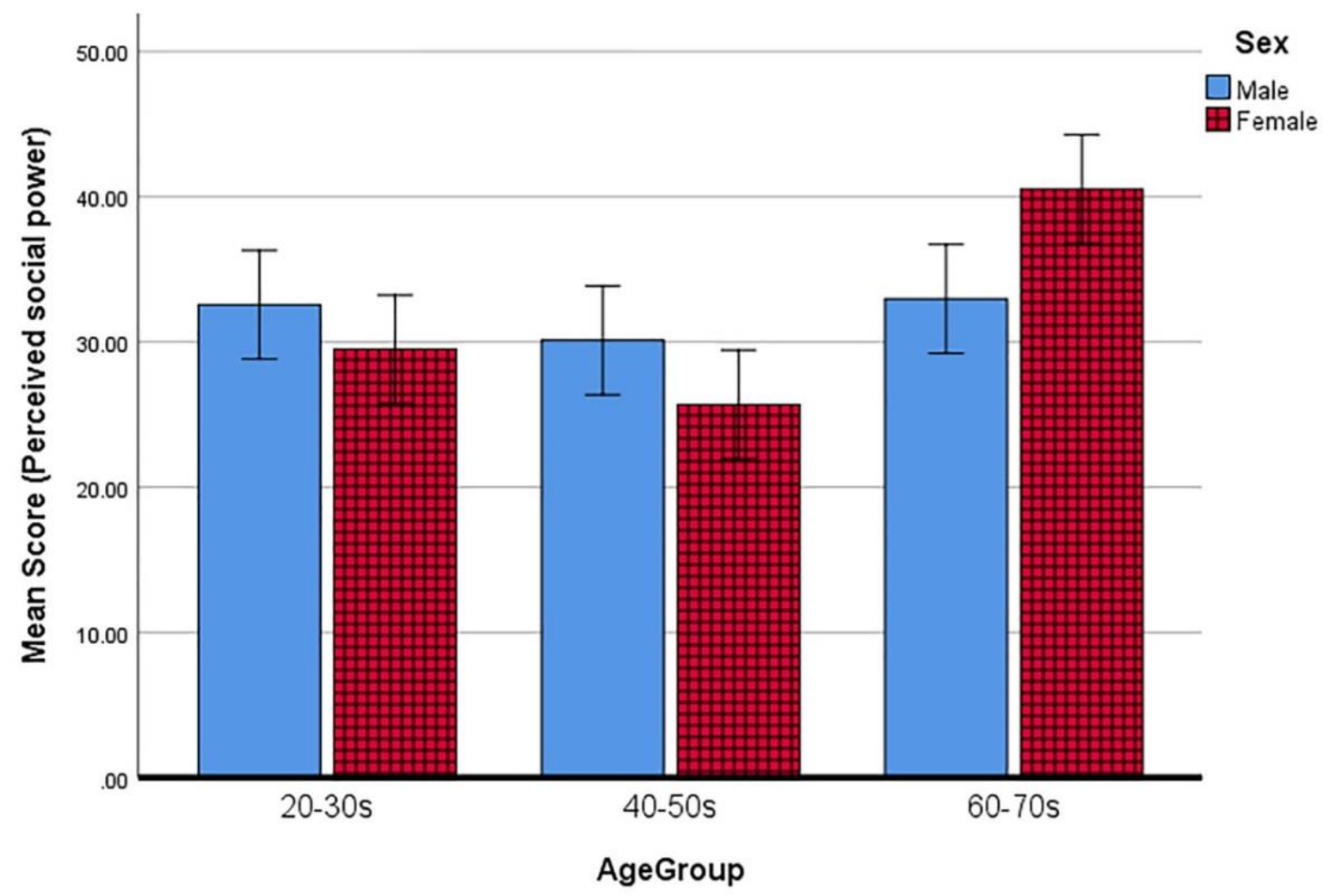

Error bars: $95 \% \mathrm{Cl}$

Figure 3 Interaction between sex and age group for mean perceived social power scores.

\subsection{Perceived Intelligence}

As with social power, for this construct there were statistically significant effects for age group and for the interaction between age group and sex (see Table 3). For the former, $F(2,114)=15.73$, pr.001, $\eta_{p}{ }^{2}=.22$, additional post hoc analysis using Bonferroni comparisons again indicating significant differences between the older age group $(M=50.43, S D=8.87)$ and both the younger $(M=41.52, S D=6.99)$ and the middle age groups $(M=42.73, S D=8.20), p<.001$, but not between the younger and middle age groups. For the interaction effect, $F(2,114)=6.91, p=.001, \eta_{p}{ }^{2}=.11$, simple effects analyses showing that while men $(M=46.03, S D=7.34)$ were perceived to be significantly more intelligent than women $(M=39.44, S D=7.82)$ in the middle age group, $t(38)=$ $2.75, p=.009$, the reverse was true in the older age group, with women $(M=53.55, S D=9.23)$ being perceived as more intelligent than men $(M=47.32, S D=7.37), t(38)=2.34, p=.024$.

In addition, when considered separately, there was a significant effect for men and women. For men $F(2,57)=3.40, p=.004, \eta_{p}{ }^{2}=.11$, the only significant difference occurring between the younger $(M=41.36, S D=7.38)$ and older $(M=47.32, S D=7.37)$ age groups. For women $F(2,57)=$ $17.35, p<.001, \eta_{p}{ }^{2}=.38$, the older age group $(M=53.55, S D=9.32)$ was perceived as significantly more intelligent than either the young $(M=41.36, S D=7.38)$ or middle $(M=39.44, S D=7.82)$ age groups. As before, regression analyses were conducted to establish whether any of the four faciometrics measures ( $\mathrm{WWHR}, \mathrm{ChP}$, LfhFfh and fWLHR) were able to predict perceived intelligence. This was consider in relation to both sex (Male, Female) and to age group (Young, Middle, Old). 
However, once again, none of outcome models were significant, indicating that faciometrics do not readily predict perceived intelligence (Figure 4).

Table 3 Descriptive statistics for age group and sex for perceived intelligence.

\begin{tabular}{rrrr}
\hline Age Group & Gender & $M(S D)$ & $95 \% \mathrm{Cl}$ \\
\hline Young & Male & $41.68(6.77)$ & {$[38.26,45.09]$} \\
& Female & $41.36(7.38)$ & {$[37.94,44.77]$} \\
Middle & Male & $46.03(7.34)$ & {$[42.61,49.45]$} \\
& Female & $39.44(7.82)$ & {$[36.02,42.85]$} \\
Older & Male & $47.32(7.37)$ & {$[43.90,50.74]$} \\
& Female & $53.55(9.32)$ & {$[50.13,56.96]$} \\
& Total Male & $45.01(7.46)$ & {$[43.04,46.98]$} \\
& Total Female & $44.78(10.24)$ & {$[42.81,46.75]$} \\
\hline
\end{tabular}

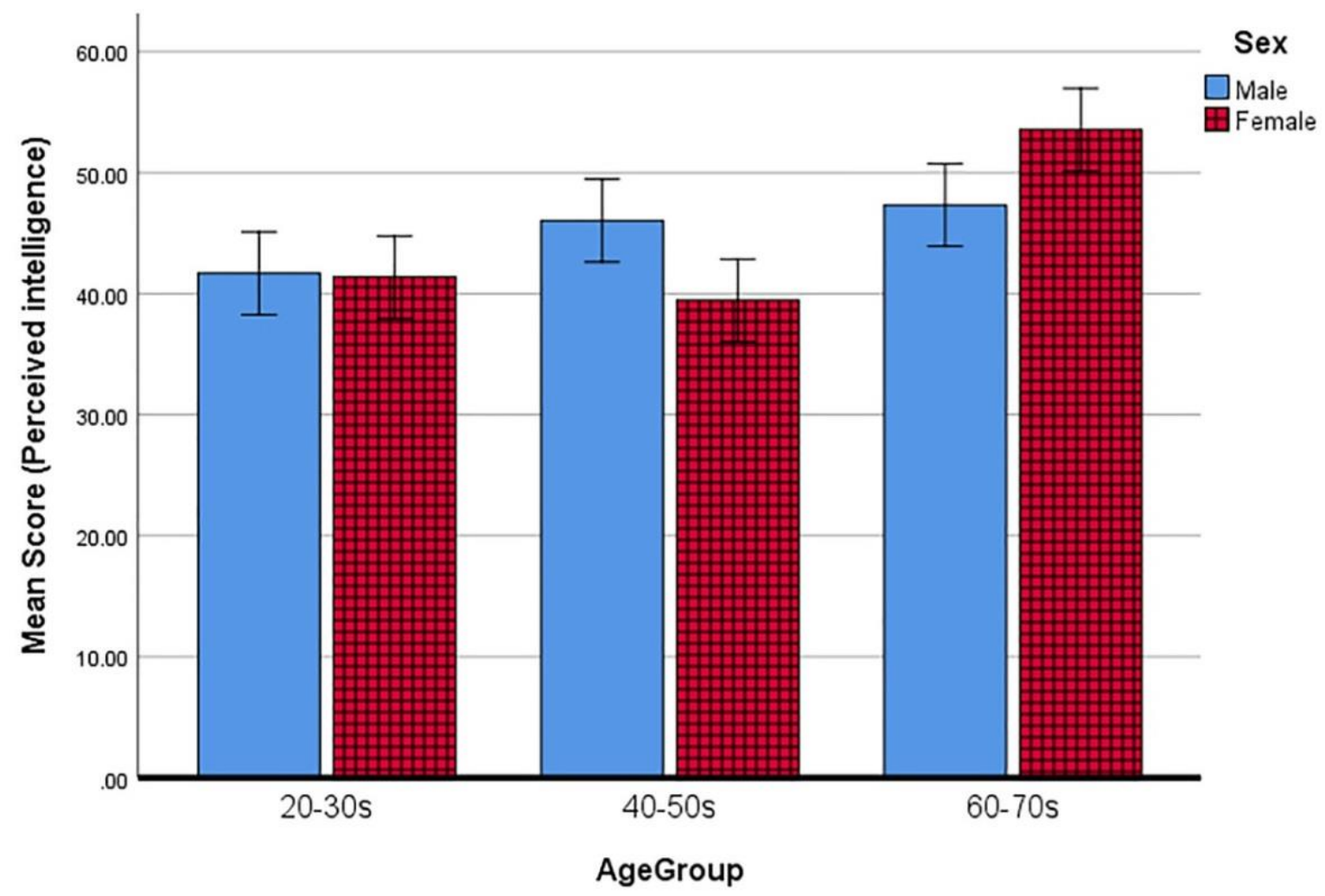

Error bars: $95 \% \mathrm{Cl}$

Figure 4 Interaction between sex and age group for mean perceived intelligence scores.

\subsection{Perceived Warmth}

For this construct no significant differences were found for age or sex, nor any interaction effect between the two (see Table 4). Faciometrics, similarly, indicated no significant relationships between them and perceptions of warmth. 
Table 4 Descriptive statistics for age group and sex for perceived warmth.

\begin{tabular}{rrrr}
\hline Age Group & Gender & $M(S D)$ & $95 \% \mathrm{Cl}$ \\
\hline Young & Male & $24.26(9.86)$ & {$[20.97,27.56]$} \\
& Female & $22.76(7.92)$ & {$[19.46,26.06]$} \\
Middle & Male & $19.99(5.11)$ & {$[16.70,23.29]$} \\
& Female & $20.52(4.70)$ & {$[17.22,23.82]$} \\
Older & Male & $21.76(6.16)$ & {$[18.46,25.06]$} \\
& Female & $23.87(9.30)$ & {$[20.57,27.17]$} \\
& Total Male & $22.01(7.42)$ & {$[20.10,23.91]$} \\
& Total Female & $22.38(7.55)$ & {$[20.48,24.79]$} \\
\hline
\end{tabular}

\section{Discussion}

\subsection{Perceived Physical Power}

As predicted, and consistent with prior findings [3], there was a significant effect for age in the perception of physical power in men, such that perceived physical power was seen to decline over the lifespan, with men in the older age group being perceived to be significantly less powerful than young men or those in middle age. Interestingly, however, this same trajectory was not perceived in the physical power of women, with no significant decline perceived over the lifespan. There were also, as predicted, significant differences in the perception of physical power between male and female faces, with male faces deemed to be more physically powerful than female faces in the young and middle aged, though this difference was lost in old age. Thus, the physical power of men and women, as a function of age, is perceived differently resulting in a significant interaction effect. At a macro level, therefore, it seems that perceptions of physical power are partly based on inter sex differences, whereas intra sex differences are only perceived in men. Why should this be? The answer may be found in the evolution of dominance hierarchies. Men and women differ dramatically in the ceiling for their reproductive effort. Whilst most fertile women will succeed in producing offspring, there will be more competition between men due to the variability in their reproductive success; dominant men will have greater access to reproductive women than subordinate males [73], particularly in polygynous societies that legitimise such reproductive strategies, $[74,75]$. Thus there is a stronger sexual selection pressure on men than on women, resulting in significant sexual dimorphism of physical size and hence power in men. Furthermore, this should be most evident when competition for mates is at its greatest, i.e. in the young and middle aged, but waning in older age as male fertility diminishes [76-78].

Whilst physical size and power is not the principal determinant for dominance and status, it remains an important one [79-85]. Nevertheless, fighting for dominance (and resultantly access to the best mates, territory, food etc.) may be an imprudent strategy, both for the loser (risking injury or death), and for the victor (risking injury in addition to other precious resources). Determining who the likely victor will be is, therefore, a key component in the success of a dominance hierarchy, and therefore accurate perception of physical power should, indeed, be a prime candidate for stereotypical assessment, and previous research supports that premise (i.e. 
that fWHR covaries with actual physical formidability, and that this cue is used to assess formidability [30]).

Do faciometrics, then, provide the baseline information from which perceptions are derived? The answer is equivocal. First, facial width to height was a significant predictor of physical power across sexes (but not by sex) in the young and middle aged, but not a predictor of physical power in the older age group, consistent with theoretical expectation and prior research [3]. However, whilst cheekbone prominence and facial width to full facial height were, like fWHR, also able to predict physical power across sexes in the middle aged but unable to do so in the older age groups, here they were also unable to predict physical power in the younger age groups. This was true also of lower face to full face height ratio, though here this was true only of the male images, with the lower face to full face height ratio of female images not predicting physical power in any age group.

That no faciometric predicted physical power in the older age group across sexes, nor generally for women, is theoretically and empirically logical. That they were fairly consistently unable to do so in the young, male age group runs counter to expectation and deserves more consideration. It seems likely that the failure to predict physical power in the expected domains may be explained by 'macro-decision making' and, potentially, by other salient cues to be considered further in the General Discussion.

\subsection{Perceived Social Power}

When considering social power, there was a significant effect for age, though unlike [3], this was evident for women but not men (the data showing no significant difference in perceived social power across the age groups). Perhaps surprisingly, social power in women was seen to be significantly greater in old age than the apparently less socially empowered younger age groups. There was also an interesting interaction effect - whereas women were perceived to be lower in social power than men in the young and middle aged groups (though not significantly so), their power significantly exceeded that of men in the older age group. From an evolutionary perspective this is, perhaps, unexpected. There is little literature that would predict that women should enjoy greater social power in any age group - the converse being more likely as a corollary of the greater power associated with men in dominance and status hierarchies as previously discussed (and see Cummins [86] for an excellent review). It has already been acknowledged that physical power is not the principal determinant for dominance and status, sexual selection pressures offering greater motivation for pursuit of status in men than women. Indeed, for men (but not women) there is a substantive positive correlation between social power and potential fertility (as estimated by copulation frequency) which would translate into actual reproductive success for men in the ancestral environment, but is negated, in the novel environment, by both contraception and cultural norms surrounding monogamy [87].

Thus, evolutionary predictions should support significant sex differences in social power with men enjoying greater social status, across age, than women. In support of this evolutionary proposition feminist research reports that, "representations of older women in the media are defined by the double marginalization of age and gender" [88], and this is a problem if, as they suggest, the media has significant influence over the way people create stereotypes about others. And yet, contrary to the frequently opposing positions of evolutionary and feminist psychologists, 
the current research suggests that women in older age are perceived to have significant social power, indeed more so than men.

It may be that the holding of power in this context may best be understood through the concept of social aging, or the age-related changes that take place in people's relationships and roles, whether that be familial, in their social network, in the workplace, places of worship or other areas of social contact [89]. Of all dimensions of aging (chronological, biological or psychological being other dimensions), social aging is that dimension most profoundly influenced by social perceptions, or the stereotyped perceptions of what aging may mean in a society's culture. It is possible, then, that the changing roles of women as they age, as mentors, facilitators, life gurus even, is being recognised and validated as part of their life story, and this positive social aging is translated into perceived social power at just such a time as male social aging is reflecting perhaps a loss of their traditional, work-place supported, power.

This would be supported by what is known as 'the Grandmother hypothesis' [90]. This suggests that at the point at which the costs of reproduction become too great, the energy expended on reproduction would be better invested in one's offspring's children, ensuring both their genetic interests as well as enhancing the social networks that may support them in terms of other resources. e.g. food, shelter etc. [91, 92]. This hypothesis is supported both theoretically through Kin Selection Theory [93, 94] and Parental Investment Theory [95] and empirically. For example, there is a considerable wealth of literature that supports the importance of allomaternal care when the mother is required to expend energy in areas other than direct care of the infant, e.g. with the Aka pygmies of Central Africa [96], and in helping with foraging in young children, both supporting learning and sustenance at the same time, e.g. in the Hadza of Tanzania [97]. Such evidence is not restricted to traditional hunter gatherer societies. A large study of altruistic behaviors of pre- and post-menopausal women, both American $(7,161)$ and Australian $(25,066)$, established that post-menopausal women devoted more time offering alloparental support, and this was not simply an artifact of greater altruistic behavior, time spent volunteering being less strongly related to menopause status [98]. It is also possible that the participants who rated the images in this study may have played a part in the recognition and validation of the role of elderly women in society. Of all participants, 94 were women with a mean age of 29.11. Additionally the mean age for the male participants was 27.5. As such, the increased demands of young parenthood would highlight the salience of alloparenting support, especially for that sex which customarily bears the mental and probable physical load of parenting and work place responsibilities.

Are faciometrics used by observers, then, in the perception of social power? Research shows, after all, that actual achievement drive, for example in US presidents, can be predicted by fWHR [37]. Nevertheless, unlike the equivocal findings of the use of faciometrics in the perception of physical power, the use of faciometrics in perceptions of social power is clear - faciometrics do not play a role in the perception of this trait. Nether in males nor females, across any age group, did any of the four faciometrics predict social power. Again, the inability to predict social power in the expected domains may be better explained by the 'macro-decision making' to be discussed. 


\subsection{Perceived Intelligence}

As with social power, analysis of the data showed a significant effect for age, with older men and women being perceived to be more intelligent than their younger counterparts. This runs slightly counter to Hehman et al's findings [3] in which no significant effect for age was seen. The current study shows older men to be perceived to be significantly more intelligent than young, but not middle aged men, with an increasing trajectory of perceived intelligence over the lifespan. For women, older women were perceived to be both significantly more intelligent than young and middle aged women. There was also, again, an interesting interaction effect mirroring that of social power. Whereas women were perceived to be significantly lower in intelligence than men in middle age, their perceived intelligence significantly exceeded that of men in the older age group.

The clear mirroring of results between social power and intelligence warrants the tentative conclusion that perceived intelligence is reflective of the changes associated with social aging as previously discussed. Whereas the social status and perceived power of women increases as they move into old age, the reverse is true of men as they leave behind their work place roles for new roles reflecting lower status within the society's culture. Thus it seems that perceived intelligence is inherently linked to social power, or the holding of power within the relevant societal culture as social power increases, so, too, does perceived intelligence.

Despite, however, the clear impact of age on perceived intelligence, faciometrics were not able to predict this trait. Neither in males nor females, nor across any age group, did any of the four faciometrics predict perceived intelligence. Explanations must be found elsewhere.

\subsection{Perceived Warmth}

Unlike physical power, social power and intelligence, neither age nor gender predicted perceived warmth. Similarly, no faciometric measure was able to predict perceived warmth, again either by sex, or by age group. Although consistent with Hehman's findings for men, it was nevertheless a surprise, the clear evolutionary prediction, based on Sexual Selection Theory, being that women would be expected to show greater warmth than men $[28,99]$ and that older men would be expected to be warmer than younger men [73]. Additionally, research supports the existence of this group stereotyping [100-102].

A probable explanation may lie in the stimuli used. Whilst extensively used in faciometric research, 2D images may enable perceptions of personality traits to be assessed more easily in some traits than others. This is supported by research showing that artificial neural networks are able to predict self-reported Big Five personality scores considerably more easily in conscientiousness than other traits [103]. It is likely that warmth may not be as easily assessed in the absence of other cues, for example, smiles, as other traits, a factor noted in common language when referring to 'mug-shots' or 'the passport-effect' - the recognition being that full frontal, neutral faces appear more severe than in 'real-life'. Though little tested, research suggests that dynamic cues do, indeed, facilitate social judgments. For example, fMRI studies show increased activity in the superior temporal sulcus when responding to horizontal eye movement and the opening and closing of the mouth - in other words, this specialised brain area is activated by facial movement quite probably underlying the interpretation of emotional expression and interpersonal communication [104]. In support, the attractiveness of an individual talking about 
enjoyable events when assessed by films has been shown to be significantly greater than their assessed attractiveness in still photos, with or without a smile [105].

The same may well be true of perceived warmth - commonly indicated cross culturally through a smile [106]. Thus age and gender differences in perceived warmth may exist but other dynamic stimuli may simply be better placed to uncover these differences than static 2D facial cues.

\section{General Discussion}

As discussed in the previous sections, our analyses indicate, across perceived physical power, social power, and intelligence, but not warmth, a significant effect for age in addition to some significant interaction effects with sex. Specifically, physical power is perceived to diminish in men (but not women), social power is perceived to increase in women (but not men), and intelligence is perceived to increase in both sexes, though men are perceived to be significantly more intelligent than women in middle age whereas that position is reversed in old age, women being perceived to be significantly more intelligent than men. Age was not shown to impact on perceptions of warmth (though note our comment on use of the stimuli employed in this study).

Prior research, as we have seen, supports the use of faciometrics in perceptions of a wide variety of traits, though there has been a dearth of literature investigating the use of faciometrics in other than student-aged populations. The current study using three age groups and four established faciometrics (fWHR, lower face to full face height, cheekbone prominence and facial width to full face height) has found, contrary to expectations, that faciometrics, almost comprehensively, do not predict the psycho-social traits of social power, warmth and intelligence, the only predictive power appreciable being in terms of perceived physical power as discussed. These findings were unexpected. Previous faciometric studies using student samples have found significant predictive power in perceptions of personality traits as earlier discussed. Further research across more diverse age groups and looking at the social heuristics in other areas is therefore needed.

In the meantime, however, an initial suggestion for these findings postulates the preferred use of macro-decision making information as the first port of call for stereotypical inferences about expected traits. Humans are skilled at facial processing, indeed the fusiform gyrus is a specialised brain area for the recognition and processing of facial information [107-110], and judgments made about personality, traits etc. tend to be almost instantaneous [4, 5] - both of these facilitate appropriate behavioural and emotional responses within the social context. Aging-associated perceptions appear to be based on criteria which facilitate this simple, quick and efficient decision making (young, middle aged or old, male or female), and are informed by socio-cultural expectation. In other words, these straightforward but effective categorizations support mental short cuts and are crucial for appropriate social interaction. That faciometrics inform macrodecision making is clear, however this study suggests that the underlying faciometrics, independent of the categorization they allow, do not provide sufficient information, at least as static, 2D information, to predict specific traits. Rather it is the use of these faciometrics, alongside other potentially salient information (e.g. skin colour and tone, facial adiposity, musculature, and so on) that allows us to categorize targets into recognized groups, from which ascriptions of trait are then made supported by socio-cultural stereotyping. 
Further research is needed, however, in those facial and body cues which may have evolved to provide salient information relevant to group living, and specifically research is needed into how these may be dynamically affected as we age. For example, further research would be welcomed in alternative measures of dominance and hierarchy, aggression and appeasement and so on, preferably employing the use of dynamic stimuli for the greatest ecological validity as earlier discussed. Additionally, the urgent need to address research on aging across ethnicities cannot be over stated, with a notable dearth of research in this area (though see [68] on the differing faciometric trajectories over time in black racial groups). It is hoped that such research may help to build a cross cultural understanding of aging-related social heuristics and the factors associated with them.

\section{Author Contributions}

Author contributions: JMR and BEK designed research; JMR provided theoretical and empirical rationale for study and discussion of findings with corresponding entries in paper; BEK collated faciometric data, and analysed with corresponding entries in paper; JMR and BEK edited paper.

\section{Competing Interests}

The authors have declared that no competing interests exist.

\section{References}

1. Buss DM (Ed.). The handbook of evolutionary psychology. John Wiley \& Sons Inc.; 2005.

2. Zebrowitz LA, Montepare JM. Appearance DOES matter. Science. 2005; 308: 1565-1566.

3. Hehman E, Leitner JB, Freeman JB. The face-time continuum: Lifespan changes in facial width-to-height ratio impact aging-associated perceptions. Pers Soc Psychol Bull. 2014; 40: 1624-1636.

4. Todorov A. Face value: The irresistible influence of first impressions. Princeton, NJ: Princeton University Press; 2017.

5. Willis J, Todorov A. First Impressions: Making up your mind after a 100-ms exposure to a face. Psychol Sci. 2006; 17: 592-598.

6. Albright L, Kenny DA, Malloy TE. Consensus in personality judgments at zero acquaintance. J Pers Soc Psychol. 1988; 55: 387-395.

7. Little A, Perrett D. Using composite images to assess accuracy in personality attribution to faces. Br J Psychol. 2010; 98: 111-126.

8. Passini FT, \& Norman WT. A universal conception of personality structure? J Pers Soc Psychol. 1966; 4: 44-49.

9. Penton-Voak IS, Pound N, Little AC, Perrett DI. Personality judgments from natural and composite facial images: More evidence for a "kernel of truth" in social perception. Soc Cogn. 2006; 24: 607-640.

10. Ambady N, Hallahan M, Rosenthal R. On judging and being judged accurately in zeroacquaintance situations. J Pers Soc Psychol. 1995; 69: 518-529.

11. Pound N, Penton-Voak IS, Brown WM. Facial symmetry is positively associated with selfreported extraversion. Pers Individ Dif. 2007; 43: 1572-1582. 
12. Hu S, Xiong J, Fu P, Qiao L, Tan J, Jin L, et al. Signatures of personality on dense 3D images. Sci Rep. 2017; 7.

13. Berry DS, Brownlow S. Were the physiognomists right? Personality correlates of facial babyishness. Pers Soc Psychol Bull. 1989; 15: 266-278.

14. Hildebrandt KA, Fitzgerald HE. Adults' responses to infants varying in perceived cuteness. Behav Processes. 1978; 3: 159-172.

15. Nittono $H$, Fukushima $M$, Yano A, Moriya $H$. The power of Kawaii: Viewing cute images promotes a careful behavior and narrows attentional focus. PLoS One. 2012; 7: e46362.

16. Kringelbach ML, Stark EA, Alexander C, Bornstein MH, Stein A. On cuteness: Unlocking the parental brain and beyond. Trends Cogn Sci. 2016; 20: 545-558.

17. Power TG, Hildebrandt KA, Fitzgerald HE. Adults' responses to infants varying in facial expression and perceived attractiveness. Infant Behav Dev. 1982; 5: 33-44.

18. Golle J, Probst F, Mast FW, Lobmaier JS. Preference for cute infants does not depend on their ethnicity or species: Evidence from hypothetical adoption and donation paradigms. PLos One. 2015; 10; e0121554.

19. Zebrowitz LA, Luevano VX, Bronstad PM, Aharon I. Neural activation to babyfaced men matches activation to babies. Soc Neurosci. 2009; 4: 1-10.

20. Zebrowitz LA, Montepare JM. Impressions of babyfaced individuals across the life span. Dev Psychol. 1992; 28: 1143-1152.

21. Zebrowitz LA, Montepare JM. Appearance DOES matter. Science. 2005; 308: 1565-1566.

22. Keating CF, Randall DW, Kendrick T, Gutshall KA. Do babyfaced adults receive more help? The (cross-cultural) case of the lost resumé. J Nonverbal Behav. 2003; 27: 89-109.

23. Glocker ML, Langleben DD, Ruparel K, Loughead JW, Gur RC, Sachser N. Baby schema in infant faces induces cuteness perception and motivation for caretaking in adults. Ethology. 2009; 115: 257-263.

24. Zebrowitz LA, McDonald SM. The impact of litigants' babyfacedness and attractiveness on adjudications in small claims courts. Law Hum Behav. 1991; 15: 603-623.

25. Volk A, Quinsey VL. The influence of infant facial cues on adoption preferences. Hum Nat. 2002; 13: 437-455.

26. Kramer RSS. Sexual dimorphism of facial width-to-height ratio in human skulls and faces: $A$ meta-analytical approach. Evol Hum Behav. 2017; 38: 414-420.

27. Haselhuhn MP, Ormiston ME, Wong EM. Men's facial width-to-height ratio predicts aggression: A meta-analysis. PLoS One. 2015; 10: e0122637.

28. Carré JM, McCormick CM. In your face: Facial metrics predict aggressive behaviour in the laboratory and in varsity and in professional hockey players. Proc Biol Sci. 2008; 275: 26512656.

29. Carré JM, McCormick CM, Mondloch CJ. Facial structure is a reliable cue of aggressive behaviour. Psychol Sci. 2009; 20: 1194-1198.

30. Zilioli S, Sell AN, Stirrat M, Jagore J, Vickerman W, Watson NV. Face of a fighter: Bizygomatic width as a cue of formidability. Aggress Behav. 2015; 41: 322-330.

31. Carré JM, Morrissey MD, Mondloch CJ, McCormick CM. Estimating aggression from emotionally neutral faces: Which facial cues are diagnostic? Perception. 2010; 39: 356-377.

32. Burriss C, Edwards S. Does facial width to height ratio predict offender aggression? J Crim Psychol. 2017; 7: 280-286. 
33. Geniole SN, Keyes AE, Mondloch CJ, Carré JM, McCormick CM. Facing aggression: Cues differ for female versus male faces. PLoS One. 2012; 7: e30366.

34. Hehman E, Leitner JB, Deegan MP, Gaertner SL. Facial structure is indicative of explicit support for prejudicial beliefs. Psychol Sci. 2013; 24: 289-296.

35. Haselhuhn MP, Wong EM. Bad to the bone: Facial structure predicts unethical behavior. Proc Biol Sci. 2012; 279: 571-576

36. Deska JC, Lloyd EP, Hugenberg K. Facing humanness: Facial width-to-height ratio predicts ascriptions of humanity. J Pers Soc Psychol. 2018; 114: 75-94.

37. Lewis GJ, Lefèvre CE, Bates TC. Facial width-to height ratio predicts achievement drive in US presidents. Pers Individ Dif. 2012; 52: 855-857.

38. Borgi $M$, Majolo $B$. Facial width to height ratio relates to dominance style in the genus Macaca. PeerJ. 2016; 4: e1775.

39. Altschul DM, Robinson LM, Coleman K, Capitanio JP, Wilson VAD. An exploration of the relationships among facial dimentions, age, sex, dominance status and personality in rhesus macaques (Macaca mulatta). Int J Primatol. 2019; 40: 5352.

40. Lefèvre CE, Wilson VAD, Morton FB, Brosnan SF, Paukner A, Bates TC. Facial width-to-height ratio relates to alpha status and assertive personality in capuchin monkeys. PLoS One. 2014; 9: e93369.

41. Martin JS, Staes N, Weiss A, Stevens JMG, Jaeggi AV. Facial width-to-height ratio is associated with agnostic and affiliative dominance in bonobos (Pan paniscus). Biol Lett. 2019; 15: 1-5.

42. Wilson $V$, Weiss $A$, Lefevre $C E$, Ochiai $T$, Matsuzawa $T$, Inoue-Marayama $M$, et al. Facial widthto-height ratio in chimpanzees: Links to age, sex and personality. Evol Hum Behav. 2020; 41: 226-234.

43. Kosinski M. Facial width-to-height ration does not predict self-reported behavioural tendencies. Psychol Sci. 2017; 28: 1677-1682.

44. Wang D, Nair K, Kouchaki M, Zajac EJ, Zhao X. A case of evolutionary mismatch? Why facial width-to-height ratio may not predict behavioural tendencies. Psychol Sci. 2019; 30: 10741081.

45. Li NP, van Vugt M, Colarelli SM. The evolutionary mismatch hypothesis: Implications for psychological science. Curr Dir Psychol Sci. 2018; 27: 38-44.

46. Danel D, Pawlowski B. Eye-mouth-eye angle as a good indicator of face masculinization, asymmetry, and attractiveness (Homo sapiens). J Comp Psychol. 2007; 121: 221-225.

47. Frackiewicz $\mathrm{W}$. The aesthetics of the eyes and mouth position in a three-point face schema. Anthropol Rev. 2001; 64: 93-100.

48. Grammer K, Thornhill R. Human (Homo sapiens) facial attractiveness and sexual selection: The role of symmetry and averageness. J Comp Psychol. 1994; 108: 233-42.

49. Milutinovic J, Zelic K, Nedeljkovic N. Evaluation of facial beauty using anthropometric proportions. Scientific World Journal. 2014; 2014: 428250.

50. Mogilski JK, Welling LLM. The relative contribution of jawbone and cheekbone prominence, eyebrow thickness, eye size, and face length to evaluations of facial masculinity and attractiveness: A conjoint data-driven approach. Front Psychol. 2018; 9: 2428.

51. Penton-Voak IS, Jones BC, Little AC, Baker S, Tiddeman B, Burt DM, et al. Symmetry, sexual dimorphism in facial proportions and male facial attractiveness. Proc Biol Sci. 2001; 268: 1617-1623. 
52. Perrett DI, May KA, Yoshikawa S. Facial shape and judgements of female attractiveness. Nature. 1994; 368: 239-242.

53. Pettijohn TF, Tesser A. Threat and social choice: When eye size matters. J Soc Psychol. 2005; 145: 547-570,

54. Coetzee V, Chen J, Perrett DI, Stephen ID. Deciphering faces: Quantifiable visual cues to weight. Perception. 2010; 39: 51-61.

55. Gray AW, Boothroyd LG. Female facial appearance and health. Evol Psychol. 2012; 10: 66-77.

56. Weston $E M$, Friday $A E$, Liò $P$. Biometric evidence that sexual selection has shaped the hominin face. PLoS One. 2007; 2: e710.

57. Penton-Voak IS, Perrett D. Female preferences for male faces change cyclically. Evol Hum Behav. 2000; 21: 39-48.

58. Hughes $S$, Bremme R. The effects of facial symmetry and sexually-dimorphic facial proportions in assessments of sexual orientation. J Soc Evol Cult Psychol. 2011; 5: 214-230.

59. Robertson JM, Kingsley BE, Ford GC. Psychometric and faciometric support for observable facial feminization in gay men. J Homosex. 2018; 66: 349-367.

60. Valentova JV, Kleisner K, Havlíček J, Neustupa J. Shape differences between the faces of homosexual and heterosexual men. Arch Sex Behav. 2014; 43: 353-361.

61. Hodges-Simeon CR, Hanson Sobraske KN, Samore T, Gurven M, Gaulin SJC. Facial width-toheight ratio (fWHR) is not associated with adolescent testosterone levels. PLoS One. 2016; 11: e0153083.

62. Feinberg DR, Jones BC, DeBruine LM, Moore FR, Law Smith MJ, Cornwell RE, et al. The voice and face of woman: One ornament that signals quality? Evol Hum Behav. 2005; 26: 398-408,

63. Koehler N, Simmons LW, Rhodes G, Peters $M$. The relationship between sexual dimorphism in human faces and fluctuating asymmetry. Proc Biol Sci. 2004; 271 Suppl4: S233-S236.

64. Lefèvre CE, Etchells PJ, Howell EC, Clark A, Penton-Voak IS. Facial width-to-height ratio predicts self-reported dominance and aggression in males and females, but a measure of masculinity does not. Biol Lett. 2014; 10: 20140729.

65. Lefèvre CE, Lewis GJ, Perrett DI, Penke L. Telling facial metrics: Facial width is associated with testosterone levels in men. Evol Hum Behav. 2013; 34: 273-279.

66. Price ME, Sheehy-Skeffington J, Sidnaius J, Pound N. Is socio-political egalitarianism related to bodily and facial formidability in men?. Evol Hum Behav. 2017; 38: 626-634.

67. Lefevre CE, Lewis GJ, Bates TC, Dzhelyova M, Coetzee V, Deary IJ, et al. No evidence for sexual dimorphism of facial width-to-height ratio in four large adult samples. Evol Hum Behav. 2012; 33: 623-627.

68. Robertson JM, Kingsley BE, Ford GC. Sexually dimorphic faciometrics in humans from early adulthood to late middle age: Dynamic, declining and differentiated. Evol Psychol. 2017; 15: 1-10.

69. Robertson J, Kingsley B. Sexually dimorphic faciometrics in black racial groups from early adulthood to late middle age. Evol Psychol. 2018; 16: 1474704918811056.

70. Wilson V, Lefevre CE, Morton FB, Brosnan SF, Paukner A, Bates TC. Personality and facial morphology: Links to assertiveness and neuroticism in capuchins (Sapajus [Cebus] apella). Pers Individ Dif. 2014; 58, 89-94. 
71. Ricanek K, Tesafaye T. MORPH: A longitudinal image database of normal adult ageprogression. Paper presented at IEEE $7^{\text {th }}$ International Conference on Automatic Face and Gesture Recognition, Southampton, UK; 2006.

72. Ebner NC, Riediger M, Lindenberger U. FACES - A database of facial expressions in young, middle-aged and older women and men: Development and validation. Behav Res Methods. 2010; 42: 351-362.

73. Puts DA. Beauty and the beast: Mechanisms of sexual selection in humans, Evol Hum Behav. 2010; 31: 157-175.

74. Betzig L. Darwinism and differential reproduction: A darwinian view of history. Hawthorne, MY: Aldine de Gruyter; 1986.

75. Betzig L. Croaks and tails or teeth and claws? Book review of Miller on mating-mind. Psycoloquy. 2002; 13: 4.

76. Araujo AB, Mohr BA, McKinlay JB. Changes in sexual function in middle-aged and older men: Longitudinal data from the Massachusetts Male Aging Study. J Am Geriatr Soc. 2004; 52: 1502-1509.

77. Harris ID, Fronczak C, Roth L, Meacham RB. Fertility and the aging male. Rev Urol. 2011; 13: 184-190.

78. Hassan MA, Killick SR. Effect of male age on fertility: Evidence for the decline in male fertility with increasing age. Fertil Steril. 2003; 79: 1520-1527.

79. Cummins DD. Social norms and other minds: The evolutionary roots of higher cognition. In Cummins DD, Allen C (Eds.). The evolution of mind. New York: Oxford University Press; 1998. p. 30-50.

80. Fink B, Neave N, Seydel H. Male facial appearance signals physical strength to women. Am J Hum Biol. 2007; 19: 82-87.

81. Toscano $H$, Schubert TW, Sell AN. Judgments of dominance from the face track physical strength. Evol Psychol. 2014; 12: 1-18.

82. Sell A, Cosmides L, Tooby J, Sznycer D, Von Rueden C, Gurven M. Human adaptations for the visual assessment of strength and fighting ability from the body and face. Proc Biol Sci. 2009; 276: 575-584.

83. Von Rueden $\mathrm{C}$, Gurven M, Kaplan H. The multiple dimensions of male social status in an Amazonian society. Evol Hum Behav. 2008; 29: 402-415.

84. Von Rueden C, Gurven M, Kaplan H. Why do men seek status? Fitness payoffs to dominance and prestige. Proc Biol Sci. 2011; 278: 2223-2232.

85. Windhager S, Schaefer K, Fink B. Geometric morphometrics of male facial shape in relation to physical strength and perceived attractiveness, dominance, and masculinity. Am J Hum Biol. 2011; 23: 805-814.

86. Cummins D. Dominance, status, and social hierarchies. In Buss DM (Ed.), The handbook of evolutionary psychology. John Wiley \& Sons Inc.; 2005. p. 676-97.

87. Pérusse D. Cultural and reproductive success in industrial societies: Testing the relationship at the proximate and ultimate levels. Behav Brain Sci. 1993; 16: 267-322.

88. Lemish D, Muhlbauer V. "Can't Have it All": Representations of older women in popular culture. Women Ther. 2015; 35: 165-180.

89. Novak M. Issues in aging (3rd ed.). Upper Saddle River, NJ: Pearson; 2012. 
90. Williams GC. Pleiotropy, natural selection, and the evolution of senescence. Evolution. 1957; 11: 398-411.

91. Alexander RD. The evolution of social behaviour. Annu Rev Ecol Syst. 1974; 5: 325-383.

92. Dawkins R. The selfish gene. Oxford: Oxford University Press; 1976.

93. Fisher RA. The genetical theory of natural selection. Oxford: Clarendon Press; 1930.

94. Haldane JBS. The causes of evolution. London: Longmans, Green \& Co.; 1932.

95. Trivers R. Parental investment and sexual selection. Chicago: Aldine Publishing Company; 1972.

96. Meehan C. Maternal time allocation in two cooperative childrearing societies. Hum Nat. 2009; 20: 375-393.

97. Hawkes K, O'Connell JF, Blurton Jones NG. Hazda women's time allocation, offspring provisioning, and the evolution of long postmenopausal life spans. Curr Anthropol. 1997; 38: 551-577.

98. Hofer MK, Collins HK, Mishra GD, Schaller M. Do post-menopausal women provide more care to their kin? Evidence of grandparental caregiving from two large-scale national surveys. Evol Hum Behav. 2019; 40: 355-364.

99. Perrett DI, Lee K, Penton-Voak IS, Burt DM, Rowland D, Yoshikawa S, et al. Effects of sexual dimorphism on facial attractiveness. Nature. 1998; 394: 884-887.

100. Cuddy AJC, Fiske ST. Doddering but dear: Process, content, and function in stereotyping of older persons. In Nelson TD (Ed.) (2002), Ageism: Stereotyping and prejudice against older persons. Cambridge, MA: The MIT Press; 2002. p. 3-26.

101. Chapman BP, Duberstein PR, Sörensen S, Lyness JM. Gender differences in Five Factor Model personality traits in an elderly cohort. Pers Individ Dif. 2007; 43: 1594-1603.

102. Fiske ST, Cuddy AJC, Glick P. Emotions up and down: Intergroup emotions result from perceived status and competition. In Mackie DM, Smith ER (Eds.). From prejudice to intergroup emotions: Differentiated reactions to social groups. New York: Psychology Press; 2002. p. 247-264.

103. Kachur A, Osin E, Davydov D, Shutilov K, Novokshonov A. Assessing the Big Five personality traits using real-life static facial images. Scientific Reports. 2020; 10: 8487.

104. Puce A, Allison T, Bentin S, Gore JC, McCarthy G. Temporal cortex activation in humans viewing eye and mouth movements. J Neurosci. 1998; 18: 21988-21999.

105. Morrison E, Grawelski L, Campbell N, Penton-Voak I. Facial movement varies by sex and is related to attractiveness. Evol Hum Behav. 2007; 28: 186-192.

106. Sauter DA, Eisner F, Ekman P, Scott SK. Cross-cultural recognition of basic emotions through non-verbal emotional vocalisations. Proc Natl Acad Sci. 2010; 107: 2408-2412.

107. lidaka T. Role of the fusiform gyrus and superior temporal sulcus in face perception and recognition: An empirical review. Jpn Psychol Res. 2013; 56: 33-45.

108. Ocklenburg S, Güntürküun $\mathrm{O}$. Recognizing yourself and others-the role of the right hemisphere for face and self-perception. In Ocklenburg S, Güntürküun $O$ (Eds.). The lateralized brain: The neuroscience and evolution of hemispheric asymmetries. London: Elsevier; 2018. p. 186-200.

109. Uppal N, Hof PR. Discrete cortical neuropathology in autism spectrum disorders. In Buxbaum JD, Hof PR (Eds.). The neuroscience of autism spectrum disorders. Oxford: Elsevier; 2013. p. 313-325. 
110. Weiner KS, Zilles K. The anatomical and functional specialization of the fusiform gyrus. Neuropsychologia. 2016; 83: 48-62.

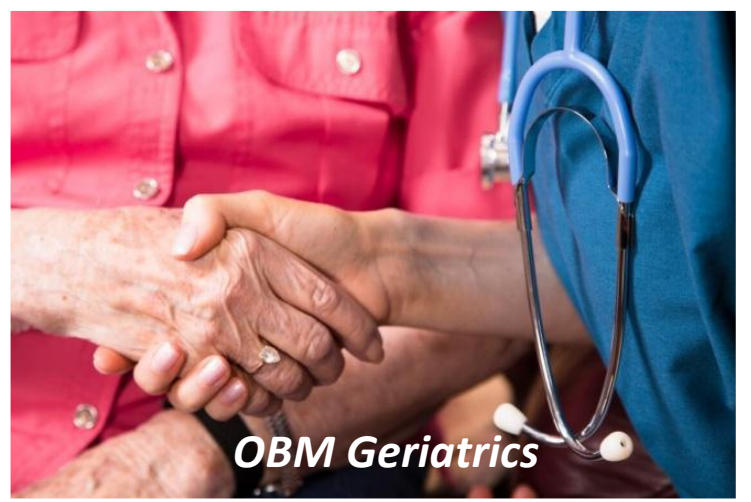

Enjoy $O B M$ Geriatrics by:

1. Submitting a manuscript

2. Joining in volunteer reviewer bank

3. Joining Editorial Board

4. Guest editing a special issue

For more details, please visit:

http://www.lidsen.com/journals/geriatrics 